\title{
Designing an Interface For a Mobile Application Based on Children's Opinion
}

\author{
https://doi.org/10.3991/ijim.v11i1.6099 \\ Radoslava Kraleva \\ South-West University “Neofit Rilski”, Blagoevgrad, Bulgaria \\ rady_kraleva@swu.bg
}

\begin{abstract}
Modern mobile devices are becoming more and more popular in children's lives. Therefore, the development of appropriate applications for them is of crucial importance. This article focuses precisely on the design of interfaces for mobile application with the participation of children. An overview of contemporary research related to Child-Computer Interaction (CCI) is made. The opinion of the children aged from 4 to 13 years on the possibilities and the features of the interface of mobile applications is investigated. The results obtained are summarized and analyzed. The prototype of a mobile application which corresponds to the preferences of the children under investigation is presented. Finally, the article specifies some future directions for research.
\end{abstract}

Index Terms - Children, mobile application for children, software engineering, child-computer interaction (CCI), mobile learning.

\section{Introduction}

Mobile technologies are closely related to the modern way of life. Young children who cannot read or write until the age of 7 in some cases, already know how to use a tablet and/or a smartphone. This is possible due to the interactive and easy to use (friendly) software products. However, it must be borne in mind that the applications suitable for children should be different from those for adults. Usually, they are funny, intuitive and interesting, hence, they keep children's attention for a long period of time. On the other hand, a poorly designed interface can have a negative impact on the cognitive skills of young boys and girls and even on their health (inappropriate font or color can damage the eyesight of children) [1].

The manner in which children perceive the surrounding world differs not only from the manner in which adults do; a difference in perception is observed between girls and boys. An example from one of the first studies comparing the perception and reaction between boys and girls during interaction with computer games is discussed in [2]. 
There are many studies concerned with the way of creating an interface suitable for children [3], the mode of interaction and skills of children when handling with the capacitive touch technology [4][5]. But most of the research is targeted at the games industry. Examples are [6], [7], [8], etc.

In 2002 Druin suggests that 'children can play in the technology design process: user, tester, informant and design partner' [9]. According to him, children as users can use the applications or devices and comment on them. As testers, they can try out the prototype and make suggestions to improve it, or simply express opinion. As informants, they are expected to participate in the design process, to express opinions, to determine how to interact with the device (or application) and the result obtained. As design partners, children have the most privileges, because they participate fully in the design of the technology. It can be considered that Druin introduces a new conception in computer design, exactly the creation of applications by children for children.

In addition to the design of games appropriate for children, regardless of the computer device, the issue of specialized computer training, in particular the mobile learning and its use by young children, has come to the fore in the recent few years. Examples of such studies are [10], [11], [12] and others.

For the proper software creation and design that are suitable for children specialists in psychology, software engineers, programmers and other children are needed. This led to the appearance of a new trend in the IT industry, called Child-Computer Interaction (CCI) [13]. It is part of Human-Computer Interaction and is mainly aimed at the study of the design, evaluation and use of computer systems in children whilst tracking the impact of technology on their emotional and social development and cognitive skills. A specialized group of researchers, called Child Computer Interaction Group (ChiCI) [14], was established. The CHECk tool was created by this working group; it observes the ethical standards, good practices and evaluation of the CCI [15].

This article presents an investigation related to the opinions of Bulgarian children, aged 4 to 13 years, on the design of mobile applications for children. A prototype of software for mobile learning for preschool children, based on the collected and summarized information, was developed.

The article is structured as follows:

- an overview of modern theories and practices in the process of designing applications for children;

- a description of the stages of designing an interface suitable for children;

- an investigation of the opinion of Bulgarian children concerning modern mobile applications;

- a prototype of a mobile device created after the analysis of the opinions of the children participating in the investigation;

- suggestions for further development of this study. 


\section{The Child User}

The child is a very interesting and different type of user of modern computer technology. They see the world in a different and unique way and they enrich their knowledge of the surrounding reality with every day. In the different age stages children develop both physiologically and emotionally, thus, their preferences and tastes change. While discovering the world around them, they form a certain idea about it and they never stop dreaming. An interesting approach to the differences in the way of perception of modern technologies by children and adults is given in [16]. Similar studies have been conducted in many other publications. Differences were found in [2] and in the manner of perception and reaction when comparing boys and girls during an interaction with computer games. Similar studies have been presented in [17], [18], [19], etc.

According to [16], children's software can fall into one of the following genres: "Entertaining education, Computer as tutor, Computer as tool, Computer as Tutee, Computer-supported collaborative learning (CSCL) ".

Debra Gelman's book [22] tracks the changes in the requirements of children of different age groups. One age group includes children within a range of two years, for example, the first group are children aged from 2 to 4; then a second group of 4 to 6 , etc. Specific applications and designs are offered and the existing designs of software are discussed in the book.

As already noted, the CCI is involved with the design, evaluation and testing of the design and development of software products suitable for children. In [20] a method for combining the existing methodologies for the creation of HCI for children is proposed so that they can easily communicate with appropriate computer devices.

An interactive design based on the interaction between a computer and a child with the help of avatar-based communication (avatar-based HCI) when using a semantic model that is necessary for the implementation of the natural communication is presented in [23].

A detailed analysis of the interaction between children from 2 to 4 years and computer devices is presented in [21]. In this research only the computer devices iPad and iPhone and the mobile application Ella are used. Mobile devices with operating systems Android and Windows Phone are not considered at all.

What must be always taken into consideration is that parents are directly involved in their children's life and studies. Therefore, the parents' opinion on the use of computer systems, and in particular mobile devices for young children, is important. Since this study is mainly directed towards Bulgaria, it should be mentioned that in [24] an investigation of the opinion of parents is presented and discussed. According to the survey, about $64 \%$ of the children use computer devices up to 2 hours a day. This confirms the idea that it is important and necessary that the software should be specialized and must meet the specific needs of the children. This is of great importance to the development of modern information systems and technologies.

A study of computing devices and media in the lives of American children aged between 8 to 18 years is presented in [25]. According to it, in $201066 \%$ of the sur- 
veyed children at the age of 8 already own an iPod. That number is increasing with each year.

A detailed review of the literature on the role of children in the design of information technology applications for children is made in [26]. The article argues that designers assume that children can have many positive ideas that can support the process of the application design which will increase its effectiveness.

There are several different theories concerning software design for children. Those of them which are adapted for children can be divided as follows:

- User-centered design [9]: With this method the users participate indirectly in the software design. Questionnaires, interviews, and users' surveys are used, thus, investigating a large group of users. However, designers are those who control the design process. Users can only give an opinion and evaluation of the design. This method is mostly used when designing apps for kids [26].

- Contextual design [27]: The software design is based on the needed information, the activities of the users in their daily life, and on the software goal. The use case scenarios and the use case diagrams are used. According to [26] this model is appropriate for software design that is child-centered context.

- Participatory design [28]: The prototype of the software product is developed together with the customers. The prototype is based on rapid prototyping without emphasizing on its functionality. This model assumes that most users can correctly define what an application should do and what data should be saved and processed. This method is not used with children because many designers refuse to accept that children can provide useful advice and ideas when designing [26].

- Cooperative inquiry [9]: This method includes the use of elements from all of the above listed methodologies for the software design, i.e., observation, questionnaires and participation of children in the software design. An interesting fact mentioned in [29] is that when children work on their own, they feel much more free, productive and creative. Otherwise, they just do what the adult expected from them. For Druin, the children from the ages from 7 to 10 years are the best possible partners in the process of the software design.

- Informant design [30]: In this method the users participate as informants in various stages of the software development, including the design. The basic assumption here is that in the design process the children are very useful since they always have unusual ideas which leads to obtaining a funny and intuitive software.

- Learner-centered design [31]: The software design is adapted towards the interests, skills and the style of students. Here the main objective in the design is what can be learned from it, how the software will be able to motivate the students, and what the training resources integrated into it are. Children participate as testers and can appreciate the resulting software but cannot participate in its design.

- Constructional design [32], [33]: The main goal is to design the software in order to provide as many opportunities for the users as possible. The idea here is that the users themselves can build their required design based on the allocation by the application. Software design and establishment of a framework for software design is performed with this method. 
- Interaction design [34], [35]: The interaction design is the discipline of defining the behavior of products and systems in response to their users.

Bearing in mind the differing theories for the software design for children together with their participation discussed above, one may conclude that children play an important role in the design and development of applications, including mobile devices. It should be noted that different children have different preferences in the different age stages and they keep changing their preferences. What is important is the designed software product should be versatile enough to satisfy the needs and tastes of as many users as possible.

\section{Stages In The Design of the Interface for Mobile Applications Appropriate for Children}

What is considered as a good user interface design [36] is the one that the user can easily and intuitively interact with the application or the system.

On the basis of the study discussed above, several important stages can be determined when designing the interface for mobile application intended for children:

1. Defining the target age group: not only the age group of children but their psycho-physiological and cognitive capabilities should be defined here. According to [37] it is difficult for children from 2 to 4 years to focus on a computer game, while those between 5 and 6 have fun and enjoy in victory.

2. Simplified design: The younger a child is, the simpler and bigger the objects onto the screen must be. This will allow the child to recognize them more easily. In addition, when working on the design it should not be forgotten that the children love the colors and their mixing. It is good when the buttons are in various colors differing from the background. If menus are used, they must be organized with buttons that do not open submenus because this often confuses the children. The icons must be large and with appropriate illustrations [22]. More about the difficulties of creating an adequate design of applications suitable for children is described in [38]. The investigation of characteristics of effective application design for smallscreen handheld devices is presented in [39].

3. Music and sounds: The proper tunes and sounds make applications even better perceived by children. Practice has proven that the musical accompaniment, be it in the form of sounds, ring tones or songs, is an important part of the perception of children. Such a study related to the role of the music and melodies as an important part of communication and perception of children is done in [40].

4. Easy tasks: Tasks should not be difficult for children. Difficult tasks would make them feel bored and avoid the use of the application.

5. Prizes: Each correctly solved task should be rewarded. This can be done with asterisks, points or any other type of image and be accompanied with a pleasant melody or a welcoming message. 
6. Privacy policy: The access to all data of the child, if she/he is under 13 years of age, should be subject to the privacy policy COPPA 2013 (Children's Online Privacy Protection Act s) [41].

7. Testing: Testing is an important part of developing integrated software. Since this is about a special group of users, namely children, the software products must be stable ones. [42] presents a methodology for investigating the consumer opinion of the children and their evaluation through the use of a specialized graphic evaluation scale.

The examined stages undoubtedly lead to the conclusion that the most important thing is to identify what the children want: what their preferences for colors, characters (assistants), tasks (targets) are and whether they like to receive awards during the interaction with the mobile application. After the children decide what they want, the adults (programmers, developers, psychologists) should understand them and establish the appropriate interface of the application. Confidentiality is an important part of building an app, but it does not depend on the opinion and wishes of children. Testing the resulting software is a different issue. This is the last stage in which the children must participate most actively and that will determine the success or failure of the mobile application.

The next section reveals an analysis of the opinions of children concerning applications for mobile devices. The survey was developed on the base of the above mentioned stages.

\section{Investigation of the Opinions of Children Regarding The Interface for Mobile Applications}

When creating applications for small children, it is of crucial importance to pay attention to their specific characteristic features. A good user interface design should be simple and easy so that it is more efficient and pleasant to work with [43].

Despite what has been stated above, it is a fact that in most cases developing children's software, in particular for mobile operating systems, is hardly ever based on research related to the opinions of children. In this section, a study of the opinions of children in Bulgaria regarding the interface and functionality of mobile applications will be presented. The idea of such a study is not new and this can be seen in the report of Janet Read [44]. A method of data collection from young children is presented in [45] as data of children's names, their place of living and even other personal information that is not important for the present study were collected.

In this study 65 children ( 32 boys and 33 girls) from Bulgaria, aged 4 to 13 years took part (Table 1). 
Table 1. Distribution by sex and age of the investigated children

\begin{tabular}{|c|c|c|c|}
\hline Age & Total & Only girls & Only boys \\
\hline 4 years & $\mathbf{9}$ & 9 & 0 \\
\hline 5 years & $\mathbf{6}$ & 3 & 3 \\
\hline 6 years & $\mathbf{1 5}$ & 0 & 15 \\
\hline 7 years & $\mathbf{6}$ & 6 & 0 \\
\hline 8 years & $\mathbf{1 2}$ & 9 & 3 \\
\hline 9 years & $\mathbf{1 2}$ & 3 & 9 \\
\hline $\mathbf{1 0}$ years & $\mathbf{1}$ & 1 & 0 \\
\hline $\mathbf{1 1}$ years & $\mathbf{1}$ & 1 & 0 \\
\hline $\mathbf{1 2}$ years & $\mathbf{1}$ & 0 & 1 \\
\hline $\mathbf{1 3}$ years & $\mathbf{2}$ & 1 & 1 \\
\hline Total & $\mathbf{6 5}$ & $\mathbf{3 3}$ & $\mathbf{3 2}$ \\
\hline
\end{tabular}

To obtain the opinion of the children a questionnaire, consisting of 10 questions was made, which they fill in with the help of their parents. The questions comply with COPPA 2013 [41] and require the signature of a parent as a sign of their agreement. In addition, the only personal data that were collected are the children's sex and age since they are important for the creation of the application which should be suitable for the age group.

In accordance with the proposed CHECk in [15], the children and their parents were fully aware of the purpose of the study; the scope of the use of the results obtained; the technology for the development of an application based on ideas proposed by them, and the purpose of its future use.

All questionnaires were completed at home when the child is in a calm emotional state. This aims at limiting the distortion of results under the influence of any worry or concern children may have had.

The first two questions were related to their age and sex, and the last question of the questionnaire was a screen of a phone on which the child was asked to draw a proposal for Interface of a game or any other application. Part of the drawings made by children of different ages, are presented in Fig. 1.

What can be concluded from the suggestions is that in $39 \%$ of the interfaces the presence of people is observed, $30 \%$ are aimed at acquiring new knowledge, and $26 \%$ show some presence of animals. Some of the children who have suggested that animals should participate in the application have drawn how they track their growing, and so they can obtain knowledge about their family, habitat, etc. An example of this is Fig. $1-$ Girl 8 years. In $26 \%$ of the drawings the affinity of children to sports games is observed. Examples are Fig. 1 - Boy 8 years and Boy 10 years. 17\% of the drawings are related to the creative ability of children to invent and to devise. Examples are numerous drawings representing the clothes and accessories to dress up the people and animals. Only $4 \%$ of the proposals related to games such as mazes and puzzles. The sum of the percentages exceeds 100 because some of the suggestions are applicable to several different groups parallel. The results are shown in Fig. 2. 


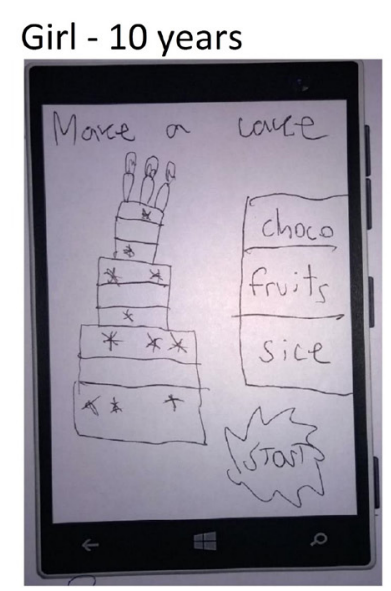

\section{Boy -8 years}

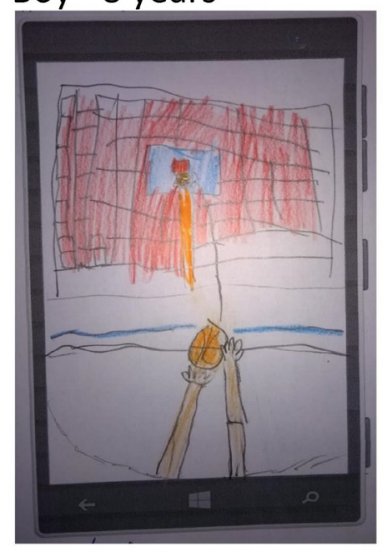

\section{Girl - 7 years}

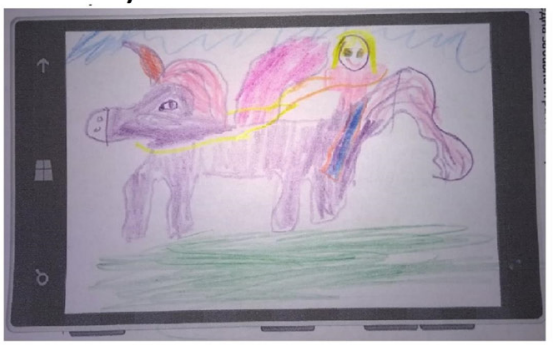

Girl - 8 years

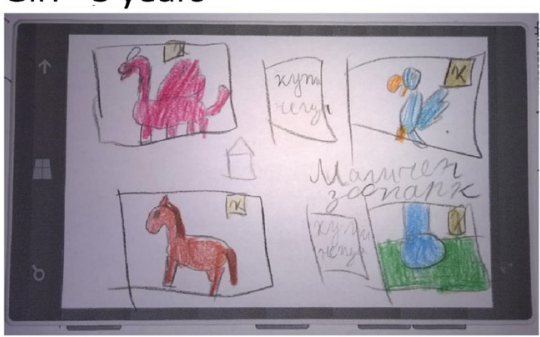

Boy - 10 years

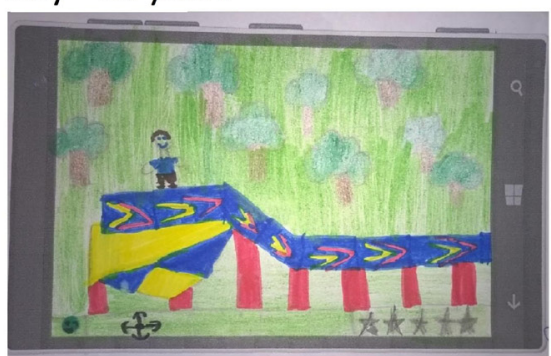

Fig. 1. Drawings of children of different age, presenting their ideas of the interface of the application

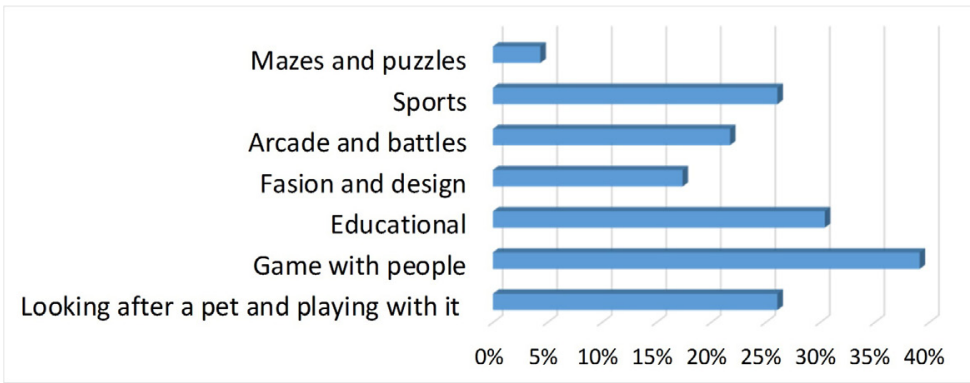

Fig. 2. Distribution of children's proposals on topics 
In a survey of parents' opinions presented in [24], parents were asked about the most used computer device by their children. The most frequent answer was "Smartphone". The children of these parents participated in this study and they defined again the "Smartphone" as the easiest-to-use (65\% of the posts). $48 \%$ of the responses were in support of the "tablet", and only $4 \%$ of the children considered the laptop (notebook) and the personal computer as easy-to-use. The data are presented in Figure 3.

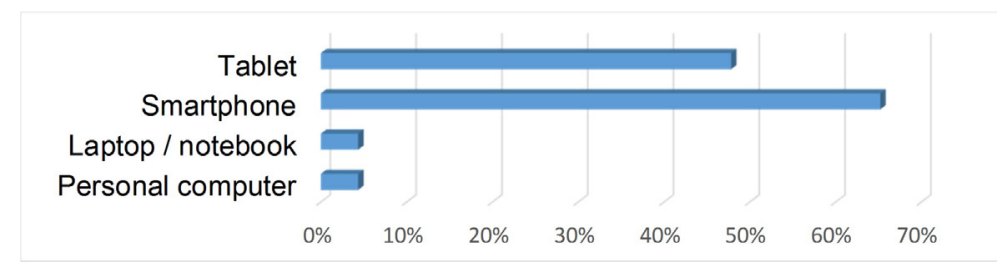

Fig. 3. Easy to use computer device according to children

The next question the children had to answer was related to their views concerning the manner of using this type of device. $96 \%$ of all surveyed children have given a positive answer to the question "is it easy to manage things on the phone (tablet) with finger?". Only $5 \%$ of them have given a negative response. These $5 \%$ are children who have used only a desktop computer up to now and have never used a smartphone or tablet.

The children answered to another important question relating to the problem presented in [46] and associated with a deficiency of free and safe applications with interface in the Bulgarian language and the recognition of children's speech of the Bulgarian language. $96 \%$ of all surveyed children felt that it would be easier and more convenient if the application uses only the Bulgarian language.

The next question in the questionnaires was related to the way of controlling the smartphone and tablet. $56 \%$ of all children have responded that the easiest way they would make it is through voice commands and gestures. $35 \%$ of all surveyed children believe that they would communicate with the sensory compact computer device only through gestures, i.e. with touches on the screen. And $2 \%$ rely on voice commands, this means that the computer device, and in particular the mobile application, must have a system specialized in recognizing children's speech in the Bulgarian language.

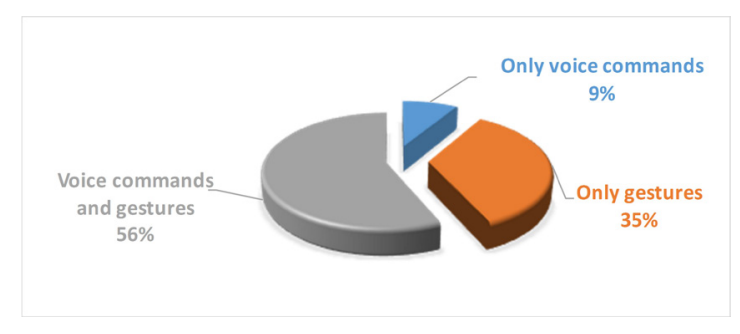

Fig. 4. The easiest way to control the smartphone and tablet 
Children love colors and mixing them. One of the questions in the survey relates to their favorite colors. The resulting data are presented in Table 2 which are summarized by gender and age.

Table 2. Summary table with data for preferred colors of children, divided by gender, age and color

\begin{tabular}{|c|c|c|c|c|c|c|c|c|c|c|c|c|c|c|c|c|c|c|}
\hline$\underset{4}{\mathscr{0}}$ & ひٌ & 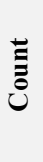 & $\stackrel{3}{\frac{0}{0}}$ & 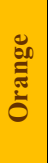 & تֶّ & 兰 & $\stackrel{\text { હ }}{\stackrel{\Xi}{\Sigma}}$ & $\frac{\overrightarrow{0}}{\grave{\partial}}$ & $\frac{0}{\mathrm{E}}$ & 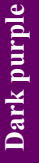 & 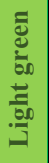 & ర్ల & 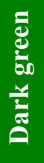 & 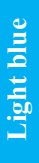 & $\stackrel{0}{\mathrm{E}}$ & 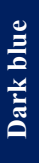 & 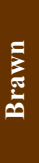 & 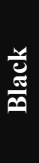 \\
\hline \multirow{2}{*}{4 years } & boy & 0 & & & & & & & & & & & & & & & & \\
\hline & girl & 9 & 9 & 6 & 6 & 9 & 9 & & 6 & 3 & 9 & & & 5 & 6 & & 1 & \\
\hline \multirow{2}{*}{5 years } & boy & 3 & & & 3 & & & & & & 3 & 1 & 3 & 1 & 2 & & & \\
\hline & girl & 3 & 1 & & & 3 & 3 & 2 & 3 & & & & & 3 & 3 & 1 & & \\
\hline \multirow{2}{*}{6 years } & boy & 15 & 9 & 2 & 6 & 2 & 2 & 1 & 1 & 1 & 1 & 12 & 6 & 10 & 14 & 2 & & \\
\hline & girl & 0 & & & & & & & & & & & & & & & & \\
\hline \multirow{2}{*}{7 years } & boy & 0 & & & & & & & & & & & & & & & & \\
\hline & girl & 6 & 2 & & 3 & & 6 & 4 & 6 & & & 6 & & & 6 & & & \\
\hline \multirow{2}{*}{8 years } & boy & 3 & & 2 & & & & & & & & 1 & & 1 & 3 & 2 & & \\
\hline & girl & 9 & & & 3 & 3 & 9 & 5 & & & 3 & 2 & & 5 & 3 & & & \\
\hline \multirow{2}{*}{9 years } & boy & 9 & & 3 & 6 & & & & & & & & 3 & 3 & 6 & 2 & & 2 \\
\hline & girl & 3 & 2 & & & 2 & 3 & 1 & 1 & & & 3 & & 2 & & & & 1 \\
\hline \multirow{2}{*}{10 years } & boy & 0 & & & & & & & & & & & & & & & & \\
\hline & girl & 1 & 1 & & & & 1 & 1 & 1 & & & 1 & & 1 & 1 & & & \\
\hline \multirow{2}{*}{11 years } & boy & 1 & 1 & & & & & & & & & & 1 & & 1 & 1 & 1 & \\
\hline & girl & 0 & & & & & & & & & & & & & & & & \\
\hline \multirow{2}{*}{12 years } & boy & 1 & & & & & & & & & 1 & 1 & & & 1 & 1 & & 1 \\
\hline & girl & 0 & & & & & & & & & & & & & & & & \\
\hline \multirow{2}{*}{13 years } & boy & 1 & 1 & & & & & & & & 1 & 1 & & & 1 & & 1 & 1 \\
\hline & girl & 1 & & & & 1 & 1 & 1 & & & 1 & & & & 1 & & & 1 \\
\hline \multicolumn{2}{|c|}{ Total: } & 65 & 26 & 13 & 27 & 20 & 34 & 15 & 18 & 4 & 19 & 28 & 13 & 31 & 48 & 9 & 3 & 6 \\
\hline
\end{tabular}

The data reveal that $74 \%$ of all surveyed children (fig. 5) (20 boys and 28 girls) have pointed out the Blue as their favorite color. More than half of the children $(52 \%)$ (32 girls and 2 boys) identified the Mauve as their favorite color. The next colors preferred by children are Light blue (48\%), Green (43\%), Red (42\%) and Yellow $(40 \%)$. The questionnaire gave the opportunity to write in additional colors, but the children did not offer any other preference out of the listed ones.

This study cannot claim to be exhaustive but it is sufficient to be considered as a starting point for determining the preferences of children for colors.

According to $83 \%$ of the children in the survey, it would be a good idea to receive a prize after every success in the application they use to play or study: whether in the form of stickers, asterisks or any other kind of bonus points. Only $21 \%$ of all children consider it superfluous and unnecessary.

Another interesting result refers to favorite characters that help the children during their interaction with the mobile application (Fig. 6). Most of the children (respective- 
ly $35 \%$ ) indicated as assistants "Little boy" or "Little girl" which corresponds to the gender of the respondents. Accordingly, $22 \%$ of the answers for a favorite assistant pointed out "Animal" and "Other". Under "Animal" some of the children mentioned specific animals such as horse, dog, cat, hamster and Pegasus. Under "Other" children wrote knight, ninja, dragon.

The results of this study can contribute to a better design and development of software oriented not only at those associated with mobile applications designed for children. The opinion of the study group can be considered as objective and not influenced by the researchers of this work.

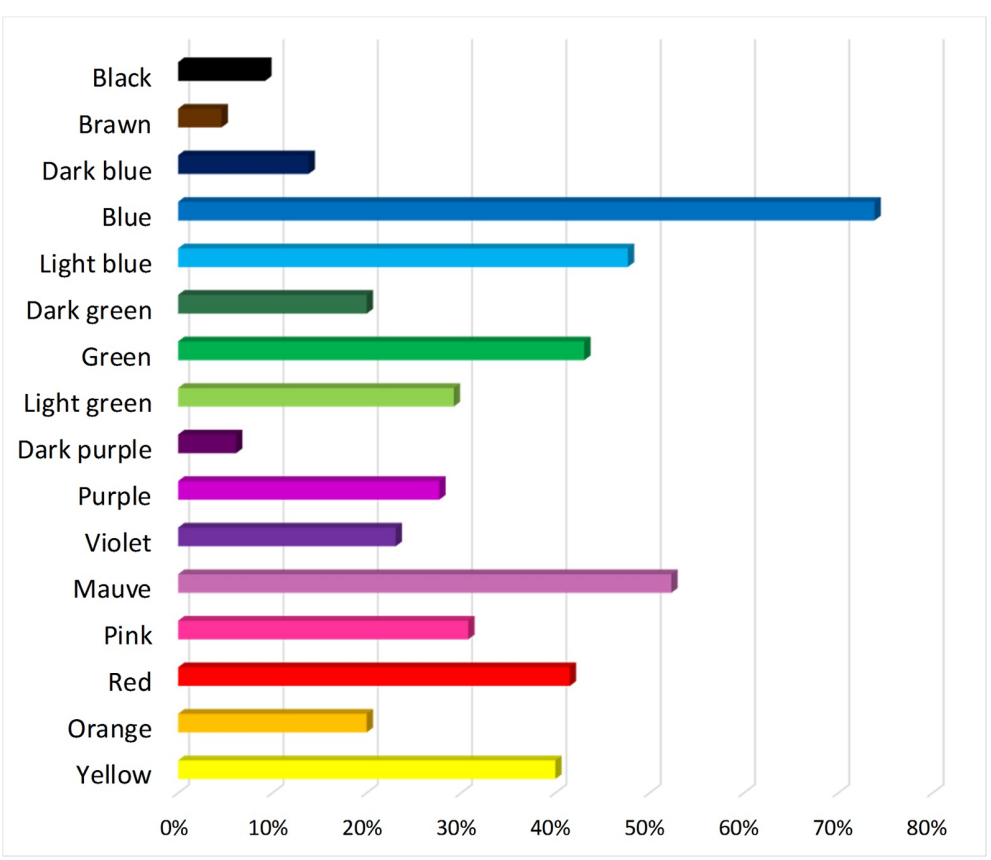

Fig. 5. Favorite colors of the children

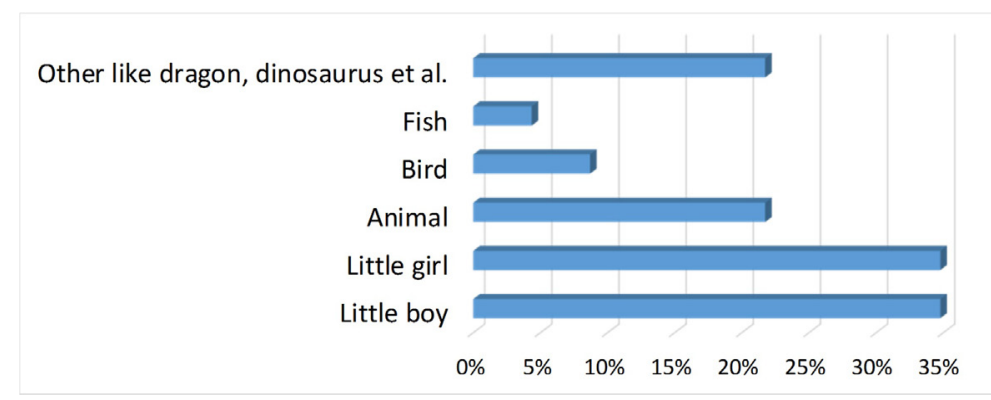

Fig. 6. Favorited characters of the children 


\section{$5 \quad$ Design Of Child Interface For Mobile Application}

For K. Y. Huang [47] the good interaction design is user-centric. It must comply fully with the perceptions and needs of the users. Moreover, the application must be designed in such a way that it should use a minimal amount of battery power and provide an efficient performance [48], [49].

The proposed prototype of a mobile application for children is based on a usercentered design (UCD) [50] since the design is built on the basis of the possibilities and the interests of the end user. The basis for the overall design are the results obtained from the investigation of the views of children in the range from 4 to 13 years of age that have been presented and analyzed in the previous section.

A conceptual design of architecture of mobile applications designed for the mobile education of young children was presented in [51]. This article appears to be its natural extension where a design of independent application is presented using two access profiles: child and parent. The application is independent because it does not require to be connected to the Internet and all data and files needed for its proper functioning are available on the mobile device. The parent receives an e-mail when a new version of the application has come out. When updating the app, the parent starts it in the parent account; after re-authentication, updating of the new version starts. When starting the application normally, there is no need to enter a password to access or to determine the role of access. The default application always starts with the role of the child.

Based on the studied children's opinions an interface for mobile application that works on the operating system Windows Phone 10 was developed. The main assistant in is a girl or boy (Fig. 7). the child can shift it if tapping twice on the character. The buttons are operated by double tap. In one tap the assistant reports what task is associated with the button. Up to the moment of writing this article the prototype of the application has only three pages „Задачки“ /"Zadachki" - Math problems/, “Буквички" /"Bukvichki” - Letters/ and "Живинки" /"Živinki" - Living creatures/. The interface is entirely in Bulgarian since this is the desire of $96 \%$ of the children. The app is named „Умничета“/"Umnicheta" - Smarty/. The melodies that accompany the actions of the game are fun and unobtrusive.

The design is entirely consistent with the limitations of screen and capabilities of mobile [52], [53]. The different pages have different wallpaper; the primary colors are influenced by the preferences of the surveyed children.

For example the page „Задачки“/"Zadachki" - Math problems/ (Fig. 8) which at present consists of:

- The page "'Броене" /"Broene" - Counting/ (Fig. 8): tasks related to the arrangement of digits from 0 to 11 of their correct positions.

- The page "Смятане" /"Smyatane" - "Calculus"/: interactive tasks for addition and subtraction.

- The page "Фигури" /"Figuri" - "Shapes"/: tasks for determining the conformity of a shape and its outline; also, searching for a square, diamond, triangle, rectangle and circle. 

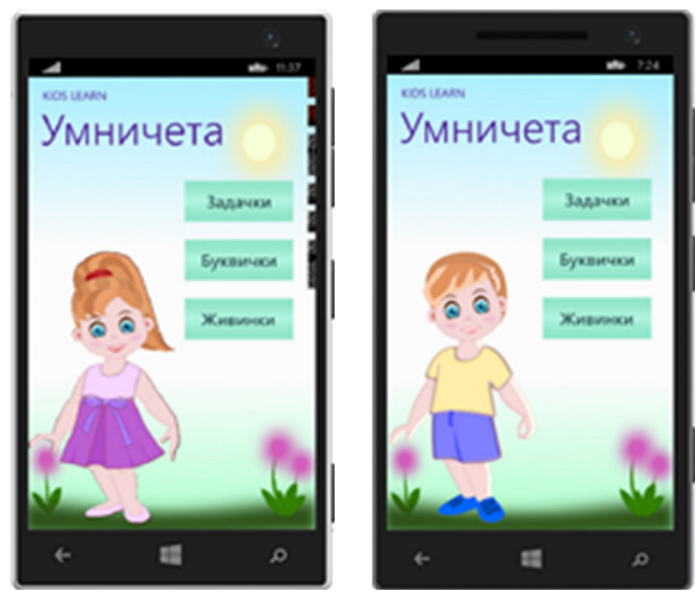

Fig. 7. The homepage of mobile application KIDS LEARN with two different assistants
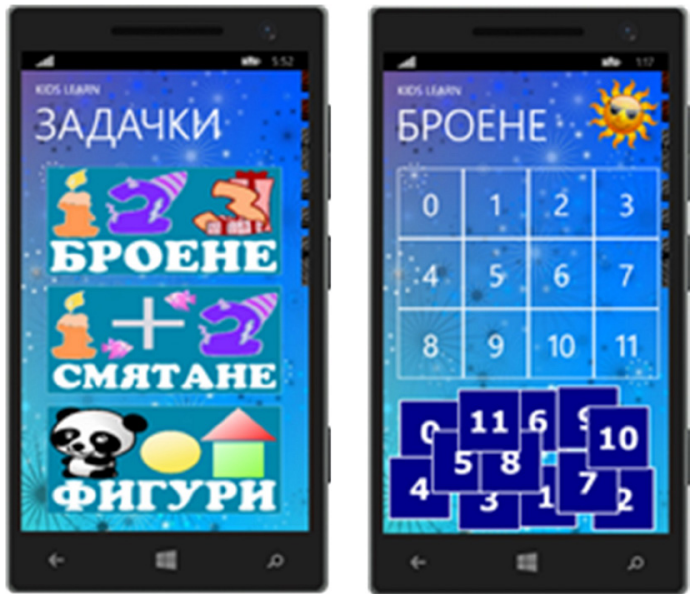

Fig. 8. The pages “Задачки" /"Zadachki" - Math problems/ and "Броене” /"Broene" - Counting/ of the mobile application "KIDS LEARN"

The button „Буквички“/”Bukvichki” - Letters/ starts the page for ordering and pronouncing Bulgarian letters.

The button "Живинки" /"Živinki" - Living creatures/ leads to a page with a choice between two different tasks. The first is to determine the geographical location of birds, animals and sea creatures. The second task is related to the distribution of animals in groups: birds, mammals, reptiles, insects and sea creatures.

The presented prototype is currently being tested by children of different ages, including those who were involved in the presented investigation. These results are going to be summarized, analyzed and presented in a future paper. 


\section{Conclusion}

Software developed together with children is a new and innovative approach where design and functionality of the application is developed in collaboration with the end user. The role of children in the design and creation of new technologies is of great importance to the quality of the obtained final product. We cannot expect them to program or to determine what training material to cover, but they can tell us what excites them and what is important and interesting for them. Children are creative and inventive; however, working with young children is definitely a challenge. However, this is the right way of getting a product that fully meets their needs.

Since mobile devices are being increasingly used by more and more people and their children in all walks of life, user interface designers and developers of mobile applications with interactive design are facing more and more challenges. What is of significance is to pay attention to the ways these applications should be attractive and at the same time suitable for all users.

This article presented a survey of the views of children in Bulgaria on the possibilities and characteristics of the interface of the mobile applications. On the basis of the obtained results a prototype of a mobile application was designed and developed. The approach of creating mobile application for children, when collaborate with other children is to be further and thoroughly researched and analyzed.

The design of the proposed apps is consistent with the preferences of the children studied, in terms of the colors, characters, and themes. Moreover, it is simple and easy to use and meets the manner of pattern perception defined in [54].

It is an undisputed fact that the use of computer equipment for training or facilitating the learning process has a beneficial effect on the increasing the intellectual achievements of children and their creative thinking [55]. On the other hand, using an inappropriate content, such as one containing aggression can affect the social interaction of children and can lead to aggressive behavior [56], [57].

This survey of children aged from 4 to 13 years reveals that at this age period there is no clear distinct preference according to the sex of the child, to the colors, characters or the way of interaction with the application. The only preference is the subject of the application itself which corresponds to a result referring to the various preferences of young boys and girls presented in [58].

The present study was important from the view point of the fact that children are happy to participate in such research and they are ready to freely offer their ideas. Although the investigation of the opinion was held among a small number of users, it is an example of effective participation in the process of the design which is an important step when designing apps for children [59].

\section{$7 \quad$ References}

1. C. Hoadley, "Chapter 4 Social impacts of mobile technologies for children: Keystone or invasive species?", in Mobile Technology for Children Designing for Interaction and 
Learning, edited by Allison Druin, Elsevier, 2009, pp. 63-81 https://doi.org/10.1016/B9780-12-374900-0.00004-1

2. D. S. Acuff, R. H. Reiher, "What kids buy and why: The psychology of marketing to kids", New York: Free Press, 1997

3. K. Wu, Y. Tang, C. Tsai, "Graphical interface design for children seeking information in a digital library", Visualization in Engineering, 2014, 2:5. https://doi.org/10.1186/22137459-2-5

4. Laili Farhana M.I., Maizatul Hayati Mogamad Yatim, "A Field Study of Understanding Child's Knowledge, Skills and Interaction towards Capacitive Touch Technology (iPad)", In proc. of 8th International Conference on Information Technology in Asia (CITA) 2013, 1-4 July 2013, pp. 1-5, IEEE, https://doi.org/10.1109/CITA.2013.6637571

5. A. N. Antle, "Analyzing children's hand actions using tangible user interfaces", in Workshop on Children and Tangibles, Conference on Human Factors in Computing Systems, ACM, April 3-9, 2009, Boston

6. K. Salen, E. Ziammerman, "Rules of play - Game design fundamentals", MIT Press, 2004

7. E. Adams, "Fundamentals of game design", Third Edition, New Riders, 2014

8. C. Fisher, "Designing games for children. Developmental, usability, and considerations for making games for kids", CRC Press, 2014

9. A. Druin, "The Role of Children in the Design of New Technology", HCIL Technical Report No. 99-23, submitted to Transactions on Computer Human Interaction, vol. 21, no. 1, pp. 20-41, 2002; http://hcil2.cs.umd.edu/trs/99-23/99-23.pdf

10. G. Vavoula, C. Karagiannidis (2005) "Designing Mobile Learning Experiences", Advances in informatics 2005, ISBN: 978-3-540-29673-7 (Print)

11. C. Chiong, C. Shuler, "Learning: Is there an app for that? Investigations of young children's usage and learning with mobile devices and apps", New York: The Joan Ganz Cooney Center at Sesame Workshop, 2010

12. Grunwald Associates LLC (2013) "Living and learning with mobile devices. What parents think about mobile devices for early childhood and K-12 learning". Available: https://www.corp.att.com/edu/docs/mobile kids.pdf

13. J. P. Hourcade (2015) "Child-Computer Interaction". Available: http://homepage.cs.uiowa.edu/ hourcade/book/child-computer-interaction-first-edition.pdf

14. Child Computer Interaction Group (2016). Available: http://www.chici.org/

15. J. C. Read, M. Hoton, G. Sim, P. Gregory, D. Fitton, B. Cassidy, "CHECk: A Tool to Inform and Encourage Ethical Practice in Participatory Design with Children", CHI'13, April 27 - May 2, 2013, Paris, France. Available: http://www.chici.org/wpcontent/uploads/2013/04/paper811.pdf

16. A. Bruckman, A. Bandlow, A. Forte, "The Human Computer Interaction handbook: Fundamentals, evolving technologies, and emerging applications", Third edition, (Chapter 36: Human-computer nitration for kids), edited by Julie A. Jacko, CRC Press, 2012, pp. 793809

17. D. Schuler, A. Namioka, "Participatory design: Principles and practices", Hillsdale, New Jersey: Lawrence Erlbaum Associates, 1993

18. P. Markopoulos, J. C. Read, S. MacFarlane, J. Hoysnieimi, "Child-computer interaction: Methodological research", Special issue of the Cognition technology and work journal, vol. 10 (2), April 2008, Springer

19. J. C. Read, S. Gilitz, "Research Methods for Child Computer Interaction", CHI'15 Extended Abstracts, Apr 18-23 2015, Seoul, Republic of Korea, pp. 2469-2470. Available: http://www.chici.org/wp-content/uploads/2013/04/p2469-read.pdf 
20. K. Lester, S. Gilutz, J. Black, "Methodology for analyzing children's understanding of computer Interfaces", in proc. of EdMedia: World Conference on Educational Media and Technology, Jun 27, 2005 in Montreal

21. N. K. Agarwal, "Use of touch devices by toddlers or preschoolers: Observations and Findings for a Single-Case Study", chapter of book New Directions in Children's and Adolescents' Information Behavior Research, edited by D. Bilal, J. Beheshi, Emerald, 2014

22. D. L. Gelman, "Design for Kids. Digital Products for Playing and Learning", Rosenfeld Media, ISBN: 1-933820-30-6, 2014

23. Z. Fang, "A structure for children-oriented Human Computer Interaction", Advanced computational intelligence (IWACI), 2011 Fourth International Workshop on, IEEE, pp. 205208, 2011 https://doi.org/10.1109/iwaci.2011.6160003

24. R. Kraleva, A. Stoimenovski, D. Kostadinova, V. Kralev, "Investigating the opportunities of using mobile learning by young children in Bulgaria", International journal of computer science and information security, Vol. 14 (4), pp. 51-55, 2016

25. V. J. Rideout, U. G. Foehr, D F. Roberts, "Generation M2: Media in the Lives of 8- to 18Year-Olds", Henry J. Kaiser Family Foundation, Menlo Park, California, 2010

26. V. Nesset, A. Large, "Children in the information technology design process: A review of theories and their applications", in Library \& Information Science Research, vol. 26, pp. $140-161,2004$.

27. H. Beyer, K. Holtzblatt, "Contextual design", ACM Interactions, vol. 6, pp. 32 - 42, 1999 https://doi.org/10.1145/291224.291229

28. D. Bilal, "Children design their interfaces for Web search engines: A participatory approach", in proc. of the 30th Annual conference of the Canadian association for information science, pp. 204 - 214, Toronto, Canada: CAIS, 2002

29. A. Druin, "Cooperative inquiry: Developing new technologies for children with children", in proc. of the SIGCHI Conference on human factors in computing systems, pp. $592-599$, New York, ACM Press, 1999 https://doi.org/10.1145/302979.303166

30. M. Scaife, Y. Rogers, "Kids as informants: Telling us what we didn't know or confirming what we knew already", in The design of children's technology (ed. A. Druin), pp. 27 - 50, Kaufmann, San Francisco, 1999

31. Y. Kafai, "Children as designers, testers, and evaluators of educational software", in The design of children's technology (ed. A. Druin), pp. 123 - 145, Kaufmann, San Francisco, 1999

32. M. Rsnick, A. Bruckman, F. Martin, "Constructional design: creating new construction kits for kids", in The design of children's technology (ed: A. Druin), Kaufmann, San Francisco, 1998.

33. M. Resnick, A. Bruckman, F. Martin, "Pianos Not Stereos: Creating Computational Construction Kits", in Interactions, vol. 3 (6), 1996

34. M. Jones and G. Marsden, "Mobile interaction design", John Wiley \& Sons, New York, 2006

35. K. Y. Huang, "Challenges in Human-computer interaction design for mobile devices", in proc. of WCECS 2009, vol. I, October 20-22, 2009, San Francisco, USA

36. M. F. Kamaruzaman, N. M. Rani, H. M. Nor, "Developing User Interface Design Application for Children with Autism", in proc. of Future academy multidisciplinary conference "ICEEPSY \& CPSYC \& icPSIRS \& BE-ci", 13-17 October 2015, Istanbul, in journal Procedia - Social and Behavioral Sciences, vol. 217, pp. 887-894, 2016; https://doi.org/10.1016/j.sbspro.2016.02.022

37. K. Ibarra, "Designing apps for kids", UX Magazine, 2011. Available: https://uxmag.com/articles/designing-apps-for-kids 
38. B. White, "Designing for Kids Is Not Child's Play", Smashing Magazine, 2016. Available: https://www.smashingmagazine.com/2016/01/designing-apps-for-kids-is-not-childsplay/

39. D. Churchill, J. Hedberg, "Learning object design considerations for small-screen handheld devices", Journal computer \& education, vol. 50 (3), pp. 881-893, 2006

40. R. Tikkanen, N. Iivari, "The Role of Music in the Design Process with Children", HumanComputer Interaction -- INTERACT 2011: 13th IFIP TC 13 International Conference, Lisabon, Portugal, 2011, pp. 288-305 https://doi.org/10.1007/978-3-642-23765-2 21

41. iUbend (2016) "A Guide to COPPA and Mobile Apps"; http://www.iubenda.com/blog/guide-coppa-mobile-apps/

42. J. C. Read, K. Fine, "Using Survey Methods for Design and Evaluation in Child Computer Interaction", Interact 2005, Rome

43. A. Darejeh, D. Singh, "A review on user interface design principles to increase software usability for users with less computer literacy", Journal of computer science, vol. 9 (11), p. 1443-1450, 2013 https://doi.org/10.3844/jcssp.2013.1443.1450

44. J. C. Read, "Children as participants in design and evaluation", forum Evaluation and usability, March-April 2015, pp. 64-66. Available: http://interactions.acm.org https://doi.org/10.1145/2735710

45. P. Markopoulos, J. C Read, S. MacFarlane, J. Hoysniemi, "Evaluating children's interactive products: Principles and practices for interaction designers", Morgan Kaufmann, 2008

46. A. Stoimenovksi, R. Kraleva, V. Kralev, "Analysis of applications suitable for mobile learning of preschool children", First student and PhD Scientific Session SDSS-2016, South-West University, Blagoevgrad, Faculty of Engineering, 19-20 May 2016

47. K. Y. Huang, "Challenges in Human-Computer Interaction Design for Mobile Devices", in proc. of the World Congress on Engineering and Computer Science 2009 VOL I, WCECS 2009, October 20-22, 2009, San Francisco, USA

48. H. S. Ashwini, A. Thawani, and Y. N. Srikant, "Middleware for efficient power management in mobile devices," in proc. of the 3rd International conference on mobile technology, applications and systems, 2006 https://doi.org/10.1145/1292331.1292387

49. Mohapatra, M. R. Rahimi, N. Venkatasubramanian, "Chapter 10. Power-Aware Middleware for Mobile Applications", Handbook of Energy-Aware and Green Computing - Two Volume Set (ed. by I. Ahmad \& S. Ranka, pp. 193-224, Chapman and Hall/CRC, 2012

50. C. Abras, D. Maloney-Krichmar, J. Preece, "User-centered design", in Bainbridge, Encyclopedia of Human-Computer Interaction, Thousand Oaks: Sage Publications, 2004. Available:

http://citeseerx.ist.psu.edu/viewdoc/download?doi=10.1.1.94.381\&rep=rep1\&type=pdf

51. R. Kraleva, V. Kralev, D. Kostadinova, "A conceptual design of mobile learning applications for preschool children", International journal of computer science and information security, vol. 14 (5), pp. 259-264, 2016

52. S. Hoober, E. Berkman, "Designing Mobile Interfaces", O’Reilly Media, 2011

53. M. Jones, G. Marsden, "Mobile Interaction Design", Wiley, 2006

54. C. Ware, "Chapter 2: Design as Applied Perception", in book HCI Models, Theories, and Frameworks: Toward a Multidisciplinary Science (ed. J. M. Carroll), $1^{\text {st }}$ edition, Morgan Kaufmann, pp.11-26, 2003; https://doi.org/10.1016/B978-155860808-5/50002-2

55. D. Clements, "Young Children and Technology", in proc. of the Forum on early childhood science, mathematics, and technology education, Washington, DC, February 6-8, 1998; http://eric.ed.gov/?id=ED416991

56. D. H. Clements, B. K. Nastasi, "Computers and early childhood education”, in Advances in school psychology: Preschool and early childhood treatment directions (ed. M. Gettinger, 
S. N. Elliott, T. R. Kratochwill), pp. 187-246, Hillsdale, NJ: Lawrence Erlbaum Associates, 1992

57. G. Forman, "Computer graphics as a medium for enhancing reflective thinking in young children", in Thinking (ed. J. Bishop, J. Lochhead, D. N. Perkins), pp. 131-137, Hillsdale, NJ: Lawrence Erlbaum Associates, 1986

58. J. Osunde, G. Windall, L. Bacon, L. Mackinnon, "An investigation of digital games features that appeal to young females and males", European conference on games based learning, pp. 694-702, 2016, in proc. of Academic Conferences International Limited, Oct 2015

59. M. Scaife, Y. Rogers, F. Aldrich, M. Davies, "Designing for or designing with? Informant design for interactive learning environments", in proc. of the SIGCHI Conference on human factors in computing systems, pp. 343 - 350, New York: ACM Press, 1997 https://doi.org/10.1145/258549.258789

\section{Author}

Radoslava Kraleva defended her Ph.D. thesis "Acoustic-Phonetic Modeling for Children's Speech Recognition in Bulgarian" in 2014. Most of her publications are focused into the study of children and their interaction with computer technologies, including recognition of children's speech in Bulgarian. Currently, she is working on her post-doctoral research related to the design and development of interactive mobile applications for children and the study of human-computer interface for young children. Now she is a chief assistant professor at the Department of Informatics, SouthWest University “Neofit Rilski”, Bulgaria. (e-mail: rady_kraleva@swu.bg).

Submitted, 03 August 2016. Published as resubmitted by the author on 15 November 2016 